\title{
O AMBIENTE DAS DÍADES DE CANAL DE MARKETING: UM ARCABOUCCO PARA ANÁLISES COMPARATIVAS
}

\section{RESUMO}

O arcabouço de economia política para a análise comparativa de díades de canal de marketing proposto por Stern e Reve (1980) concentrava-se principalmente nas ralações entre os membros dos canais. Este artigo amplia o arcabouço de economia política, indicando como fatores ambientais, portanto externos, a uma díade poderiam influenciar e afetar a estrutura e os processos da díade. Q uando combinado com 0 artigo original de Stern e Reve, a perspectiva geral resultante deve fornecer uma base abrangente para o desenvolvimento de teorias na área de canais de marketing.

\section{Ravi Singh Achrol}

George Washington University

\section{Torger Reve}

BI Norwegian School of Management

\section{Louis W. Stern}

Northwestern University

\footnotetext{
ABSTRACTT he political economy framework for the comparative analysis of marketing channel dyads proposed by Stern and Reve (1980) focused mainly on relationships between channel members. This article extends the political economy framework by indicating how environmental factors (i.e., factors external to a dyad) might influence and affect the structure and processes of the dyad. When combined with the original article by Stern and Reve, the resulting overall perspective should provide a comprehensive basis for theory development and research in the marketing channel area.
}

PALAVRAS-CHAVE Economia política, canais de marketing, análise comparativa de díades, fatores ambientais.

KEYWORDS Political economy, marketing channels, comparative analysis of dyads, environmental factors. 
Segundo o arcabouço da economia política para a análise comparativa de canais de marketing (Stern e Reve, 1980), uma díade de canal de marketing pode ser analisada em termos (1) de sua economia interna, ou seja, de sua estrutura e seus processos econômicos internos, e (2) de sua política interna, ou seja, de sua estrutura e seus processos sociopolíticos internos.

- A estrutura econômica interna é descrita pelo tipo de forma transacional que liga dois membros do canal, ou seja, os esquemas econômicos verticais internos de uma determinada díade, indo das transações mediadas pelo mercado às hierárquicas.

- Os processos econômicos internos referem-se à natureza dos mecanismos decisórios usados para determinar os termos de negociação entre os membros da díade, abrangendo decisões impessoais e rotineiras, barganha e processos de planejamento centralizado.

- A estrutura sociopolítica interna é definida pelo padrão de relações de dependência de poder que há entre quaisquer dois membros do canal, indo do poder mínimo ao poder desequilibrado e centralizado, passando pelo equilibrado.

- Os processos sociopolíticos internos são descritos em termos dos sentimentos dominantes, como cooperação e/ou conflito, presentes na díade.

Como indicado no artigo original que delineou o arcabouço de economia política, as tarefas que restam para concluir o arcabouço são: (1) identificar as interações e variáveis que fogem à dinâmica interna do intercâmbio diádico, que tem a maior influência sobre a estrutura e os processos de uma díade; e (2) sugerir como esses fatores externos poderiam ser organizados de modo teoricamente esclarecedor.

A significância do ambiente de um canal não se encontra bem refletida na literatura sobre teoria e pesquisa de canais. Foram feitas referências a condições externas como possíveis determinantes da estrutura do canal (por exemplo, Bucklin e Carman, 1974; Sturdivant, 1966), mas faltam investigações explícitas da natureza e do impacto das variáveis externas. Mesmo nas raras investigações que há (por exemplo, Etgar, 1977), as conclusões parecem apenas aguçar a consciência de que permanece muito fragmentado o conhecimento dos impactos ambientais.

Este artigo sugere um arcabouço ambiental que pode ser acoplado ao arcabouço anterior que lida com as interações internas. Antes de prosseguir, contudo, algumas observações e advertências devem ajudar o lei- tor a entender e apreciar as limitações de nossa tentativa de captar todas as variáveis ambientais críticas no limitado espaço de um artigo.

1. Este artigo propõe um arcabouço, não uma teoria. Um arcabouço pode ser visto como um primeiro passo para identificar e dimensionar as principais variáveis que influenciam e organizam a estrutura e os processos das entidades sociais. É, antes de tudo, uma tentativa de delinear as variáveis e mapear um campo de interação. Assim sendo, um arcabouço não pretende ser uma teoria. Pelo contrário, seu objetivo é ajudar a situar as pesquisas individuais para que possam avançar sistemática e metodicamente rumo à emergência de um paradigma teórico dominante (veja Zal tman, Lemasters e Heffring 1982).

2. 0 arcabouço ora apresentado se apóia em seis pressupostos básicos: (a) o intercâmbio bipartite, "diádico", representa a unidade fundamental de análise; (b) o ambiente de uma díade focal pode ser dividido em ambientes primário e secundário da tarefa, e num ambiente macro; (c) os ambientes primário e secundário da tarefa de uma díade focal podem ser divididos em setores de insumos, de produção, competitivo e regulador; (d) o arcabouço original da economia política pode ser diretamente aplicado ao estudo das interações ente díades focais e os ambientes primários de sua tarefa; (e) o ambiente secundário da tarefa pode ser mais bem descrito em termos de determinadas dimensões "qualitativas" que têm impacto sobre o intercâmbio diádico; e (f) as influências ambientais macro se manifestam por meio de desdobramentos no ambiente secundário da tarefa de uma díade focal.

3. Incluiu-se uma série de proposições ilustrativas que podem fornecer pistas sobre o uso desse arcabouço para possíveis previsões e para indicar potenciais fontes de teoria.

4. Atendendo ao objetivo de um arcabouço abrangente, este artigo é de al cance extremamente amplo. 0 objetivo foi atingido a expensas de maior detalhamento, e alguns tópicos foram meramente indicados ou referidos.

M ais adiante, apresentamos o diagrama geral das dimensões do arcabouço proposto e as definições em que se sustenta sua estrutura. Em seguida, discutimos as dimensões variáveis que propomos como as de maior utilidade para descrever as influências ambientais a partir de diferentes setores da estrutura. Contudo, antes de voltarmos à matéria básica do arcabouço, fornecemos uma breve justificativa quanto à unidade de análise es- 
colhida, a díade de canal, já que ela representa um construto essencial em torno do qual orbita o próprio arcabouço.

\section{A DÍADE COMO UNIDADE DE ANÁLISE}

Neste artigo, como no anterior (Stern e Reve, 1980), ad otamos a perspectiva de que a ati vidade fundamental nos canais de marketing é a transação, ou seja, o ato de troca entre dois agentes econômicos. As transações se consumam para a realização das diversas funções de marketing que compreendem a atividade do canal. Com efeito, qualquer sistema interorganizacional pode ser definido em termos das transações que ali ocorrem entre agentes sociais.

O foco sobre as transações como atividade básica leva a uma perspectiva diádica em que se enfatiza a relação entre as partes transacionais. A abordagem diádica não é de todo nova (veja Evans, 1963), mas suas aplicações ao marketing são relativamente poucas (por exemplo, Bonoma, Bagozzi e Zaltman, 1978; Reve e Stern, 1982; Sheth, 1976). Ao contrário da maioria das abordagens existentes, que se concentram seja na empresa individual ou no canal como um todo, o foco sobre a análise no nível transacional se dá em como e por que diferentes transações são criadas, realizadas ou evitadas entre os membros do canal. Além disso, a análise das transações no canal se concentra nas eficiências relativas associadas a modos alternativos de concluir transações, como integração vertical, arranjos contratuais e intercâmbio no mercado (confira Williamson, 1975).

No futuro, o estudo das relações interorganizacionais em canais de marketing provavelmente acabará por assumir a forma de análise de redes em vez de díades. A análise de redes captaria mais plenamente a complexidade das relações interorganizacionais (Aldrich e Whetten, 1981). Para estudar as redes de interações interorganizacionais, contudo, é preciso antes compreender a transação básica ou 0 ato de troca entre pares de agentes sociais, por meio da aplicação de um modelo de interação diádica. De fato, Aldrich e Whetten reconhecem que "o ponto de partida de todos os estudos de agregados organizacionais é uma relação ou transação entre duas organizações" (Aldrich e Whetten, 1981, p. 385).

É de extrema importância entender que, ao definir uma díade como a unidade de análise, não há nenhuma restrição à possibilidade de existência de elos significativos entre duas ou mais partes de um sistema em canal. De fato, a própria necessidade de especificar um arcabouço externo ou ambiental visa permitir um tratamento metódico de tais influências extradiádicas, como, por exemplo, compreender o que ocorre com as transações bilaterais quando interage uma terceira influência. Nesse sentido, a díade fornece um limite conveniente a partir do qual se pode examinar a natureza de uma ampla gama de forças "externas".

Outro forte motivo para a escolha da díade como unidade de análise é o fato de que um arcabouço deve ser útil para o desenvolvimento e o teste de teorias. Enquanto o estado das teorias quanto às interações interorganizacionais diádicas vem se aprimorando (confira Pfeffer e Salancik, 1978; Williamson, 1975), o estado da teoria das redes ou sistemas ainda é relativamente fraco e caótico. Como observam Bonoma, Bagozzi e Zaltman (1978, p. 58), "nesse estágio de desenvolvimento, a 'teoria' dos sistemas é principalmente uma ferramenta descritiva ( por exemplo, o fluxograma), que não admite formulação rigorosa de hipóteses, testes, ou formulação de teorias". 0 foco sobre a transação e, portanto, sobre o intercâmbio diádico tende a permitir que a pesquisa dos canais de marketing avance mais e com maior rapidez do que a dependência das generalidades algo nebulosas encontradas na teoria dos sistemas. Mas, para justificar tal foco, é imperativo que a pesquisa responda por todas as interações significativas externas à díade que sobre esta podem incidir. 0 arcabouço aqui proposto é um esforço para garantir que todas essas variáveis relevantes sejam anotadas.

\section{O AMBIENTE DAS DÍADES DE CANAL DE MARKETING}

Não há um ambiente único para todos os membros de uma díade de canal. Cada força exógena que incide sobre uma relação diádica pode ser considerada um contexto ambiental separado. Mas, tanto do ponto de vista da expediência analítica quanto da generalização teórica, é razoável admitir que haja agrupamentos importantes de forças que parecem afetar de maneiras diferentes as díades de canal. Teoricamente, o pluralismo ambiental das díades de canal pode ser abordado por meio da distinção entre as forças que criam dependências externas diretas e indiretas para uma díade. Assim, há para cada díade um ambiente primário da tarefa, um ambiente secundário da tarefa e um ambiente macro da tarefa. 
- O Ambiente Primário da Tarefa se compõe dos fornecedores e clientes imediatos da díade. Em algumas situações, os órgãos reguladores e os concorrentes da díade de canal podem ser trazidos para relacionamentos diretos e, portanto, para o ambiente de tarefa primário.

- O Ambiente Secundário da Tarefa se compõe dos fornecedores, dos fornecedores imediatos, dos clientes, dos clientes imediatos, dos agentes reguladores e dos agregadores de interesses que os influenciam, e dos concorrentes diretos e em potencial da díade de canal.

- O A mbiente M acro abrange forças sociais, econômicas, políticas e tecnológicas gerais que afetam as atividades nos ambientes primário e secundário das tarefas. ${ }^{1}$

$\mathrm{Na}$ análise teórica dos ambientes, é de vital importância obter um insight quanto à natureza das dependências e influências externas. Em primeiro lugar, as opções estratégicas disponíveis para os agentes do canal em sua adaptação ou reação às forças ambientais estão fortemente restritas pela natureza e proximidade dessas forças. Reagindo a elas, os membros da díade podem considerar diversas formas de integração, entre as quais fusão, cooperação espontânea, cooperação negociada, etc. (cf. Pfeffer e Salancik, 1978), além de estratégias para aumentar seu próprio poder por intermédio de atos como a diversificação. Por outro lado, os acontecimentos que se dão no ambiente de tarefa secundário são menos afeitos à absorção ou à influência individual. Esforços conjuntos por meio da formação de coalizão e da cooperação horizontal são mais eficazes. Além disso, mudanças no ambiente macro normalmente não podem ser aproveitadas proativamente com muito sucesso, e as estratégi as de adaptação, como retirada, por exemplo, representam a única resposta eficaz.

A segunda alavancagem importante proporcionada pela generalização teórica vem do tipo de variáveis que tendem a ser úteis para fornecer explicações. Como os el ementos do ambiente de tarefa primário são agentes identificáveis com que se lida frente a frente, as variáveis e interações especificadas no arcabouço de economia política interna (Stern e Reve, 1980) assumem relevância direta. M as os el ementos do ambiente secundário e macro, como o estado tecnológico do setor, a orientação para o bem-estar social e os sistemas legais e reguladores, relacionam-se com a díade focal por meio de grande variedade de processos e complexas interações de mediação, filtragem e amortecimento. Dessa maneira, apenas construtos de ordem mais abstrata, em vez de variáveis operacionais espe- cíficas, podem ser suficientemente abrangentes para permitir a generalização que é própria da teoria.

Além de dividir o ambiente em fenômenos primários, secundários e macro, também é de valia segmentálo em termos dos principais setores com que qualquer díade precise se relacionar. Conseqüentemente, para os fins de um arcabouço abrangente, os ambientes primário e secundário das tarefas precisam ser divididos em um setor de insumos, um de produção, um competitivo e um regulador (Dill, 1958; Thompson, 1967):

- 0 setor de insumos do ambiente de tarefa de uma díade de canal éformado por todos os fornecedores diretos e indiretos da díade.

- O setor de produção é formado por todos os clientes diretos e diretos da díade de canal, sejam distribuidores ou usuários finais. Os setores de insumos e produção se referem às relações verticais em termos do canal de marketing.

- O setor competitivo capta principalmente as relações horizontais com que se depara a díade de canal, ou seja, os concorrentes atuais e em potencial da díade de canal.

- 0 setor regulador é formado por grupos reguladores, inclusive órgãos governamentais, sindicatos patronais, organizações de defesa de interesses especiais e grupos ad hoc.

Voltamo-nos agora para os principais componentes conceituais do arcabouço representado na Figura 1.

\section{0 conceito de díade focal}

Um modelo de interação em díade toma as relações de troca entre duas partes um objeto fundamental ou fenômeno a ser explicado. Em tal modelo, o comportamento de marketing é tido como uma atividade inerentemente social em que os resultados da troca dependem dos arranjos estruturais, da barganha, do poder, do conflito e das imagens afetivas ou cognitivas compartilhadas pelo comprador e pelo vendedor (Bagozzi, 1978, Carman, 1980, Stern e Reve, 1980). Ao isolar díades para análise, é preciso compreender quatro conceitos fundamentais.

Primeiro, a díade focal é qualquer relação de troca entre duas partes que esteja sob exame. Assim, embora isso possa ser o mais comum, não é necessário que a díade focal em tela corresponda a agentes hierarquicamente adjacentes ao canal de distribuição formal . 0 canal formal é normal mente reconhecido como a rota seqüencial por onde passam os fluxos físicos e/ou de 
titularidade de bens e serviços. 0 canal se define enquanto sistema de ação social de maneira muito mais ampla e abrange toda a ordem de elos e relações. Por exemplo, os canais formais de muitos fabricantes envolvem a passagem dos pedidos por atacadistas independentes para chegar a varejistas independentes. Mas esses mesmos fabricantes também podem manter relações diretas com seus varejistas, auxiliando na apresentação e nas promoções no ponto-de-venda, no planejamento de estoques, na publicidade local e outros. Sempre que haja interação direta e voltada a metas entre os agentes de um canal, existe uma díade de canal.

Em segundo lugar, se todas as interações sociais voltadas a metas criam el os diádicos, então as "transações" referem-se a mais do que a mera troca de recursos físicos ou monetários, incluindo, também, trocas que envolvam informação, fundo de comércio/identificação, legitimidade social, influência, etc. N esse sen- tido, troca organizacional é qualquer atividade entre duas ou mais organizações que traga conseqüências, reais ou previstas, para a consecução de suas respectivos metas e objetivos. ${ }^{2}$

Uma frase fundamental da definição é a consecução de metas. Sugerimos que as interações que não sejam voltadas a metas são por demais tênues para que se as possam qualificar como trocas. Assim, fundos de comércio e identidade podem ser trocados, desde que estejam envolvidas conseqüências efetivas ou previstas para a consecução de metas. Essa caracterização preserva a natureza fundamental de toma-lá-dá-cá e negociação da troca.

Em terceiro lugar, não se deve confundir a díade "focal" com a idéia de um conjunto central ou crucial de agentes/el os que sejam fundamentais para a operação de um sistema de canal específico. A díade focal é assim chamada para permitir distinção do nível da ca-

Figura 1 - Ambiente das díades de canais de marketing.

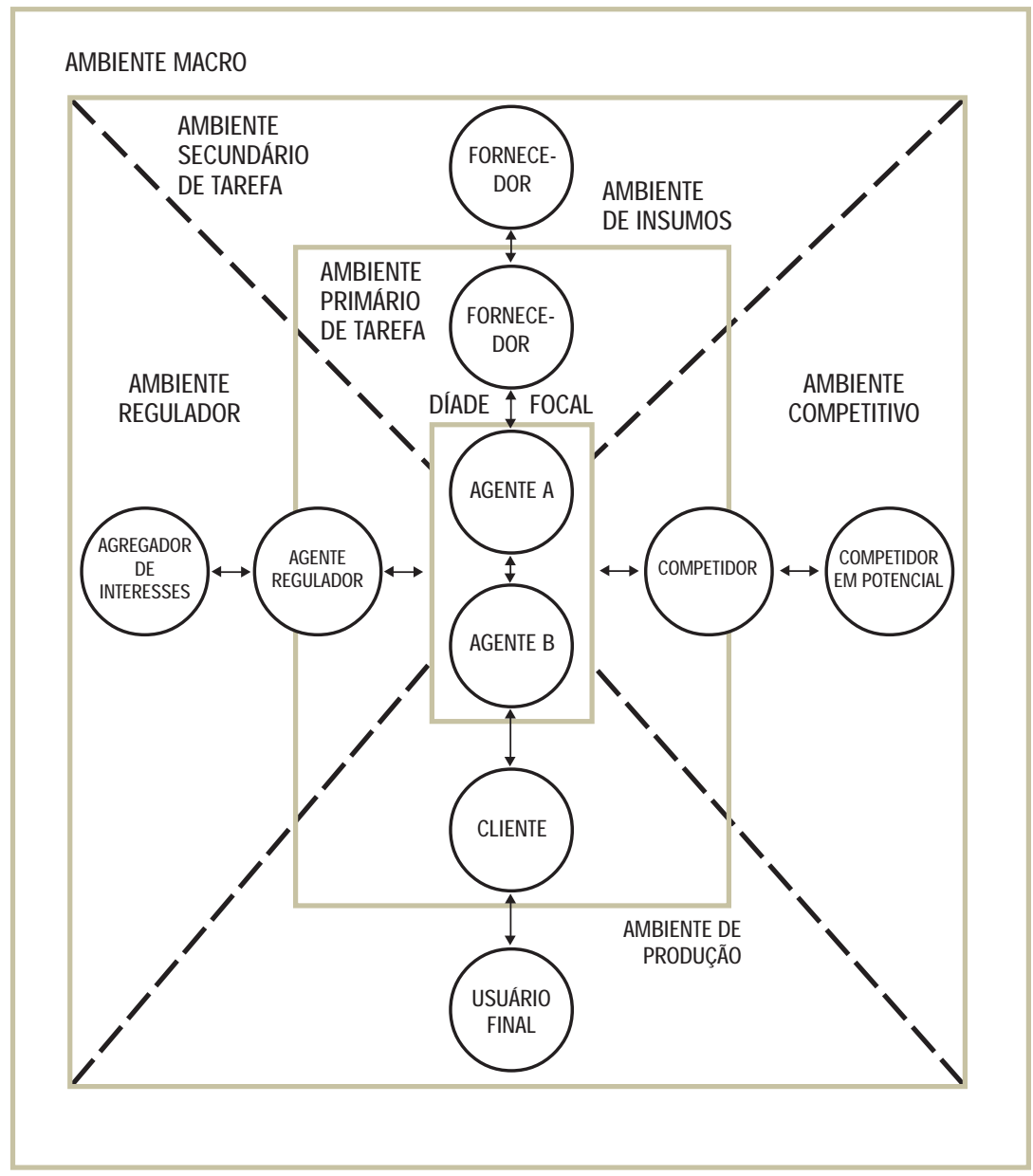


deia de distribuição que está em foco num dado estudo. Assim, fabricante-atacadista, atacadista-varejista, fabricante-varejista e até fornecedor-fabricante representam díades focais arquetípicas que poderiam ser 0 foco de estudo de uma determinada pesquisa. A necessidade de distinção do nível de distribuição como ponto focal é importante para a aplicação desse arcabouço porque essa especificação permitirá definições consistentes dos ambientes primário e secundário, rel evantes para o universo de amostragem de qualquer estudo.

Finalmente, os testes empíricos com hipóteses só podem ser conduzidos para uma amostra de díades específicas ou singulares. Embora uma díade singularmente identificada possa apresentar diversos traços particulares e diferen ças individuais, como personalidades, diferentes políticas de branding ou ênfase dada à prestação de serviços, estes não devem impedir a aplicação de um arcabouço que leve ao desenvolvimento ou ao teste de teorias. Se uma teoria for forte, os traços singulares das díades compostas de unidades ou agentes individuais do canal se resumirão a pequenos termos residuais. Se for fraca, a parte explicada da variância será menor, o residual será maior e a validade, robustez e/ou generalidade da teoria correria o risco de rejeição.

\section{Análise de interações com o ambiente de tarefa primário}

Cada agente que opera fora de uma díade de canal específica faz parte do ambiente da díade. 0 que está aqui em questão é como a relação entre os "de fora" e os "de dentro" pode ser descrita de maneira que seja eventual mente possível fazer previsões quanto aos efeitos nas relações de troca da díade e de seu ambiente. Evidentemente, na abordagem transacional do estudo do comportamento social a natureza da relação ou do elo tende a ser central. Para um grande número de agentes externos, mais especificamente aquel es que se encontram no ambiente de tarefa primário da díade, é possível definir a relação que mantém com a díade como sendo transacional. Assim como cada transação realizada pelos membros da díade com partes externas também a envolve, por definição, numa troca diádica, as variáveis internas de economia política aplicam-se a todas essas transações, onde quer que ocorram. Noutras termos, pode-se dizer que essas interações podem ser abordadas por meio de um "modelo ampliado de economia política" de troca. Por exemplo, no caso de uma díade fabricante-atacadista, fornecedores e clientes institucionais, como varejistas, estão entre os agentes mais importantes dos setores de insumos e de produção do ambiente primário da díade de canal. As relações entre os membros do canal comercial que operam fora da díade e os membros da díade podem ser freqüentemente estruturadas e, em al guns casos, administradas. Assim, as relações podem ser descritas em termos de (1) ocorrerem entre as partes transações de mercado ou hierárquicas (estrutura econômica); (2) que mecanismos de tomada de decisão sejam usados para estabelecer os temos de troca entre elas (processos econômicos); (3) ser o poder mínimo equilibrado, desequilibrado ou centralizado (estrutura política); e (4) quais os tipos de sentimentos e comportamentos (cooperativo/conflitante) que tipificam suas interações ( processos políticos).

Observações idênticas podem ser feitas sobre os agentes do setor competitivo e do setor regulador do ambiente primário da tarefa se houver relação de troca entre eles e os membros da díade focal. Assim, na Figura 1, os concorrentes e agentes reguladores estão posicionados na fronteira entre os ambientes primário e secundário, indican do que as relações podem ser diretas ou indiretas. Por exemplo, se houver um cartel, os concorrentes estarão envolvidos em transações com pelo menos um dos membros da díade focal. E se um membro da díade mantiver uma relação de troca relativamente próxima com um agente regulador, como a existente entre uma companhia de transporte rodoviário e a Comissão de Comércio Interestadual, ou entre uma cooperativa agrícola e o Departamento de Agricultura, as variáveis de economia política poderão ser prontamente utilizadas para posicionar os relacionamentos. Como no caso de uma transação de mercado sujeita a barganha e/ou planejamento centralizado, onde o poder costuma ser desequilibrado e os processos de al ocação de recursos muitas vezes são altamente cooperativos e normalmente apresentam conflito mínimo. Evidentemente, as trocas com agentes externos no setor competitivo e no regulador podem não envolver a troca de bens ou serviços por dinheiro, mas essas trocas são tão importantes para a díade focal como as que envolvem trocas monetárias.

Em suma, como regra geral, as variáveis e a perspectiva delineadas no arcabouço interno da economia política aplicam-se diretamente a qualquer relacionamento externo que envolva troca direta entre alguém "de fora" e qual quer dos membros da díade focal. Essa rede de trocas diretas deve ser consi derada a arena estratégica fundamental da anál ise do canal. Para a construção e 0 teste de teorias nesse contexto, as teorias e proposi- 
ções "micro" indicadas no arcabouço intermo da economia política (Stern e Reve, 1980) devem fornecer forte poder explicativo para lidar com influências vindas dos setores de ambiente primário da tarefa.

Quando os elementos ambientais influenciam o caráter da troca en tre al guém "de fora" e um membro da díade, mas não partiêpam diretamente da transação propriamente dita, ficam além do al cance analítico do arcabouço de economia política. Assim, a tarefa por realizar exige que isolemos as variáveis que devem ser aplicadas a relações que não as de troca entre uma díade de canal e seu ambiente. Esses elementos normalmente se encontram no ambiente secundário da tarefa e no ambiente macro das díades de canal. Como essas forças não podem ser especificadas nos termos do modelo de economia política, as proposições ilustrativas oferecidas adiante irão se concentrar no desenvolvimento de esclarecimentos e na indicação de fontes teóricas a respeito dos efeitos dessas forças sobre as relações político-econômicas entre os agentes que interagem na díade focal.

\section{Análise do impacto dos ambientes secundário e macro sobre as díades de canal}

Acreditamos haver duas abordagens alternativas à identificação de todas as influências ambientais que não entram no intercâmbio, mas que estão presentes nos ambientes secundário e macro das díades de canal. U ma é conceber as díades focais ou organizações individuais como se reagissem a recursos/agentes ambientais específicos que as contemplam, mas sem estarem envolvidos em qualquer forma de troca direta. Alternativamente, podemos definir o ambiente como uma realidade dinâmica, porém amorfa (sem forma, tamanho nem elementos bem definidos), que possa, contudo, ser caracterizada em termos de suas qualidades ou dimensões abstratas.

Segundo a tradição anterior, os agentes do ambiente secundário da tarefa podem ser estudados especificamente em termos dos recursos que controlam e do poder que poderiam, potencial e indiretamente, exercer frente a movimentos considerados pela díade focal. Da mesma forma, o estado e as al terações por que passam os recursos específicos do ambiente macro, tais como o nível de desenvolvimento tecnológico, a infraestrutura de comunicação, crescimento econômico/ ciclos econômicos ou mudanças demográficas, podem ser observados como variáveis que afetam a díade focal e suas relações socioeconômicas. De acordo com essa tradição, al guns estudiosos das organizações pro- curaram isolar as características objetivas do ambiente que têm conseqüências significativas para a estrutura organizacional, mecanismos de controle, sistemas de informação e estratégias adaptativas e proativas. Por exemplo, Black e Kase (1963) estudaram o ambiente das agências de reabilitação da saúde mental no contexto de populações e necessidades em mutação, categorias de enfermidade, tecnologia médica e conceitos de prática profissional. Aiken e Alford (1970) estudaram a inovação em habitações populares em termos de cultura política, concentração de poder na comunidade, nível de pobreza e diferenciação, continuidade e integração comunitárias.

Pelos motivos práticos, metodológicos e teórico-conceituais a seguir, acreditamos que adotar essa tradição para a análise de canais seria de pouca valia.

Primeiro, o problema de usar um subconjunto de variáveis reais, objetivas (elementos ambientais), é que tal abordagem implica inventariar 0 ambiente. 0 inventário de itens (elementos) ambientais é imenso, para dizer o mínimo. Por exemplo, poderíamos escoIher variáveis como nível de renda, taxa de juros, tecnologia, tendências populacionais, ciclos de negócio e intensidade competitiva e, ainda assim, mal teríamos começado a adentrar o problema. $\mathrm{Na}$ verdade, a maioria dessas variáveis poderia ser decomposta em subvariáveis (como intensidade competitiva em função do porte e número dos competidores, caráter institucional dos competidores, competição por preços, competição por outros valores que não o preço e assim por diante), fazendo com que o problema da especificação das variáveis relevantes seja trabalho para toda uma vida, se não mais.

Em segundo lugar, nem todos os eventos enfrentados por uma organização a afetam necessariamente porque a organização ou está isolada ou protegida de determinados el ementos ambientais, ou os eventos são por demais insignificantes para exigir resposta. É a isso que se referem os teóricos das organizações quando dizem que as organizações são "fracamente acopladas" [loosely coupled] ao ambiente. Como observaram Pfeffer e Salancik (1978),

Se os atos organizacionais fossem completamente determinados por cada evento em mutação, as organizações estariam constantemente frente a desastres em potencial e precisariam monitorar todas as mudanças e, ao mesmo tempo, modificar-se continuamente. 0 fato de que os impactos ambientais são sentidos de 
forma imperfeita dá às organizações al guma liberdade de ação, além de Ihes conferir a capacidade de agir em relação a horizontes de tempo mais longos do que 0 necessário para que um ambiente mude. (PFEFFER e SALANCIK, 1978, p. 13).

Em terceiro lugar, a generalidade de tais "itens de efeito" é extremamente tênue em relação ao tempo e à situação. Por exemplo, é possível encontrar em qualquer momento fortes correlações entre um avanço tecnológico e o nível de conflito no sistema investigado. Mas é improvável que uma tecnologia específica venha a ocorrer novamente no futuro. Ademais, pode não ser a tecnologia em si a causa do conflito, mas o uso do poder em sua assimilação ou al guma outra variável interveniente.

Em quarto lugar, temos que, pelo fato de os itens de efeito comportarem baixa generalização e ainda serem complicados por um sem-número de interações, será pequena a probabilidade de se desenvolver uma sólida tradição científica apoiada empiricamente. Quando há relações diretas de troca entre agentes externos e membros da díade, vimos ser possível identificar um arcabouço formal de definição de relacionamentos que sirva de base para gerar proposições teóricas (veja Stern e Reve, 1980). Mas quando não há trocas diretas e as influências são mediadas, filtradas e amortecidas por diversas variáveis e diversos processos intervenientes, 0 poder de prever reações específicas a itens é reduzido, restando sempre um resíduo de incertezas.

Considerando-se esses problemas, a tradição alternativa, que requer dimensionar 0 ambiente, tende a ser mais produtiva, especial mente na análise dos ambientes secundários de tarefas. A adoção dessa tradição costuma exigir a construção de instrumentos de mensuração a partir de uma lista tão abrangente quanto possível de variáveis ambientais específicas e objetivas. A lista pode ser reduzida e/ou focada por meio de pesquisa preliminar mediante métodos arquivais, de levantamento ou observacionais. 0 que será porventura extraído dos dados, uma vez colhidos, é um conjunto de variáveis qualitativas que descrevem com parcimônia os principais fatores ambientais e se prestam ao desenvolvimento de proposições teóricas. A Figura 2 apresenta algumas das dimensões qualitativas do ambiente conceitualizadas por teóricos das organizações que adotam essa tradição para a análise do ambiente.

Embora acreditemos que essa abordagem tenda a ser rica em esclarecimentos para a análise de influências no ambiente secundário da tarefa, sua utilidade é de início questionável no que tange à análise do ambiente macro. Evidentemente, o nível de desenvolvimento tecnológico, a riqueza, o consumo e a poupança, o crescimento, as mudanças demográficas,

Figura $2^{\mathrm{a}}$ - Exemplos de dimensões qualitativas do ambiente.

Capacidade ambiental (rica/ pobre): abundância relativa de recursos de insumos e de produção disponíveis para uma organização dentro de seu "domínio" de operação.

Homogeneidade-heterogeneidade ambiental: grau de semelhança ou diversidade entre elementos da população abordada, inclusive organizações, indivíduos e forças sociopolíticas que afetem os recursos. Uma dimensão correlata, e possivelmente mais abrangente, é a da simplicidade-complexidade ambiental, que se refere diretamente à complexidade da tomada de decisão. Quanto menor o número e maior a homogeneidade dos insumos informacionais necessários para a tomada de decisão, mais simples 0 ambiente. Quanto maior o número e a heterogeneidade dos insumos informacionais, mais complexo 0 ambiente (veja Duncan, 1972).

Estabilidade-instabilidade ambiental: taxa de variabilidade ou giro dos elementos do ambiente.

Concentração-dispersão ambiental: na medida em que os recursos de insumos e de produção disponíveis são controlados por poucas ou muitas organizações, pessoas ou localizações, ou nelas concentrados.

Turbulência ambiental: na medida em que os ambientes são afetados por interligação ambiental e uma crescente taxa de interligação.

a Desenvolvido a partir de Aldrich, 1979, p. 63-74. Para outras maneiras de abordar as dimensões ambientais, veja Child (1972), Duncan (1972), Emery e Trist (1965), Jurkovich (1974), Lawrence e Losch (1967), Pfeffer e Salancik (1978), Starbuck (1976), Terreberry (1968), Thompson (1967). 
a infraestrutura de comunicação e de transportes e outros fatores de uma economia determinam em grande medida o tipo de sistemas de distribuição e de programação vertical que nela evoluem. M as quando a análise de canais se concentra em díades individuais, o estado da economia pode ser tratado como dado para a maioria dos horizontes de tempo previsíveis. Os processos de mudança mais contínuos têm impactos menos radicais, e esses efeitos se fazem sentir principalmente no ambiente secundário de tarefa. Ademais, para fins de análise comparada, seja estática ou dinâmica, o impacto significativo do nível ou das mudanças das variáveis ambientais macro costuma se dar em termos do caráter "institucional" das organizações do canal.

Infelizmente, não há hoje, na teoria, base empiricamente testável para prever o caráter e a direção da mudança institucional frente a qualquer nível ou direção especificável de mudança em qualquer das variáveis ambientais macro. Assim, ao evocar um arcabouço de análise comparada das díades de canal de marketing, propomos ser melhor fundar tal arcabouço no considerável raciocínio teórico que vê nos elementos do ambiente de tarefa secundário os efeitos das forças ambientais macro. Diz a teoria que as organizações não percebem propriamente seu ambiente, mas de alguma forma ordenam um ambiente. Como afirma Weick (1969),

[...] 0 ambiente é um fenômeno atrelado a processos de atenção, e [...] não havendo atenção para com 0 ambiente ele simplesmente não existe.

Em vez de falar sobre adaptação a um ambiente externo, pode ser mais correto afirmar que 0 ato de organizar consiste em adaptar-se a um ambiente ordenado, constituído pelos atos de agentes humanos interdependentes. (WEICK, 1969, p. 27-28).

Nossa posição fundamental é que, para os membros de um canal em díade focal, a percepção ordenada do ambiente macro é representada pelo conjunto de organizações, e ainda pode ser medida por esse mesmo conjunto de organizações e processos em interação. Esses processos constituem os ambientes primário e secundário de tarefas da díade.

Em suma, sugerimos que uma abordagem administrável e teoricamente interessante à conceitualização do ambiente de uma díade de canal deveria se basear: 1. no ambiente primário de tarefa caracterizado essencialmente em termos das economias políticas em interação, afetadas por
2. forças amorfas do ambiente secundário de tarefa, mais bem caracterizadas em termos de dimensões qualitativas abstratas, enquanto

3. se leva em consideração o estado das mudanças do ambiente macro apenas na medida e nos termos de seu impacto sobre as dimensões qualitativas do ambiente secundário de tarefa.

No restante do artigo, ilustramos a importância de considerar as forças externas, geradas por fatores extra-intercâmbio, em termos de dimensões abstratas, e desenvolvemos, por meio da aplicação do arcabouço aqui sugerido, algumas proposições ilustrativas quanto às mudanças político-econômicas ocorridas na díade focal por conta dessas forças.

\section{DIMENSÕES AMBIENTAIS E COMPORTAMENTO DA DÍADE DE CANAL}

Usando o arcabouço ambiental acima delineado, podemos fazer al gumas previsões sobre os atos e os estados comportamentais nas relações da díade de canal sob condições ambientais específicas. Para tanto, nos concentraremos principalmente no construto da incerteza ambiental. Há, na literatura das organizações e da economia institucional, amplo apoio ao fato de que a incerteza é uma dimensão ambiental fundamental que afeta as organizações (sua estrutura e seus processos internos), as relações interorganizacionais e o modo e os custos de transacionar (confira Aldrich, 1975, 1979; Lawrence e Lorsch, 1967; Pfeffer e Salancik, 1978; Thompson, 1967; Williamson, 1975). Pfeffer e Salancik (1978, p. 68) observam que a "incerteza [...] pode ser vista como um resultado das demais dimensões ambientais" (veja, também, Lawrence, 1981, p. 316).

U ma das principais fontes de incerteza éa variabilidade ou a instabilidade dos recursos e/ou influências presentes no ambiente (Child, 1972). Além disso, a percepção e a magnitude da incerteza ambiental experimentada pelos membros da díade são funções da complexidade ou heterogeneidade do ambiente (Duncan, 1972; Emery eTrist, 1965; Lawrence L Lorsch, 1967; Thompson, 1967; Williamson, 1975). Em outras palavras, quanto mais numerosas as unidades de informação necessárias para a tomada de decisões e quanto mais aleatoriamente elas estiverem distribuídas num ambiente heterogêneo, mais incerto será o ambiente. A tomada de decisão e a coordenação diádicas também se tornam incertas se a disponibilidade de recursos for escassa (ou seja, se a capacidade 
ambiental for exígua; veja a Figura 2), e se o ambiente de produção e/ou insumos for concentrado. Assim, quanto mais distantes os ambientes de tarefa estiverem da riqueza, da homogeneidade, da estabilidade, da dispersão e da placidez (em oposição à turbulência), maior incerteza deverá se esperar.

A incerteza ambiental influencia a estruturação e o funcionamento das díades de canal de marketing. Em termos de sua estrutura econômica interna, uma díade pode ir da mediação do mercado a algum nível de integração vertical, em termos de mudanças de propriedade ou contratuais. Tais desdobramentos não tendem a se manifestar a curto prazo. 0 efeito mais imediato pode ser uma al teração dos equilíbrios de poder percebidos entre os agentes (estrutura política), dos processos funcionais como negociação de novos termos de transação (processo econômicos) ou dos sentimentos dominantes de conflito e cooperação (processos políticos).

Alternativamente, ou além disso, um ou ambos os agentes pode movimentar-se (a) de maneira a operar sobre a fonte externa de incerteza para obter algum controle sobre ela, ou (b) para buscar se proteger de seus efeitos. Por exemplo, no primeiro caso, o fabricante de uma díade fabricante-varejista poderia, dependendo da fonte de incerteza, estabelecer um elaborado sistema de informações para monitorar e prever acontecimentos, ou recorrer a maiores estratégias de diferenciação e promoção de um produto para reforçar a fidelidade à marca no mercado de produção. No segundo caso, o varej ista poderia procurar diversificar seu sortimento de produtos, isolando-se, assim, ao reduzir suas dependências externas. Nos dois casos, se as medidas adotadas forem bem sucedidas, 0 agente em questão acumula maior poder frente ao outro membro da díade e pode usar esse poder para causar maiores alterações internas na díade, no futuro. Por outro lado, se a fonte de incerteza vier de setores laterais (reguladores ou competitivos) e não verticais (insumos ou produção) do ambiente, os dois agentes poderão buscar al guma espécie de acordo cooperativo com as fontes de incerteza (estabelecendo assi m elos diretos onde antes não existia nenhum, e atraindo a fonte para uma economia política negociada). Todas essas estratégias somente surtem efeitos visíveis a longo prazo. ${ }^{3}$

As subseções a seguir procurarão desenvolver esses fenômenos em proposições testáveis. Pedimos ao leitor que tenha em mente duas questões importantes. Primeiro, nosso objetivo é simplesmente indicar a utilidade do arcabouço para a análise transacional em canais de marketing. Não fazemos nenhuma tentativa de propor ou aplicar alguma teoria que abranja 0 ambiente em todas as suas dimensões ou pretenda explicar todos os aspectos do comportamento diádico. M esmo na teoria das organizações, da qual foram tomadas muitas dimensões conceituais, não se pode dizer que haja, hoje, um paradigma dominante. Veja, por exemplo, em Van de Ven e Joyce, 1981, discussões do estado da arte sobre os principais paradigmas. Isso significa que a pesquisa sobre contextos de canais deve concentrar-se principalmente no desenvolvimento da teoria (cf. Zaltman, Lemasters e H effiring, 1982. Ao mesmo tempo, significa que os pesquisadores estarão explorando diversas linhas teóricas, al gumas delas conduzindo a previsões conflitantes e freqüentemente resultando na desagradável situação em que nos deparamos com a previsão de que, se $X$ não ocorrer, então ocorrerá $Y$. $O$ desenvolvimento de uma teoria suficiente e a especificação das condições que prescrevem um resultado em detrimento de outros são pré-requisitos necessários para que se possa desenvolver qualquer conjunto de hipóteses que sejam abrangentes e inteiramente coerentes. Não é o que pretendemos fazer a seguir.

Em segundo lugar, o construto da incerteza ambiental deve ser abordado com cautela. Dizer que os ambientes são incertos, muito embora isso seja comum em parte da literatura organizacional e econômica, constitui provavelmente um erro epistemológico. Estritamente falando, é a organização que é incerta a respeito de seu ambiente, de modo que o volume de incerteza manifestada é, na verdade, uma função do "ajuste" entre a organização (estrutura, sistemas de informação, processos decisórios e capacidades) e as qualidades ambientais indicadas na Figura 2, e não destas últimas entre si. É de se esperar, então, encontrar organizações (em nosso contexto, o das díades de canal) que tenham desenvolvido estruturas e processos adequados para lidar de modo eficaz com ambientes considerados "incertos" e neles sobreviver. Nesse sentido, as proposições abaixo devem ser lidas no contexto de uma dinâmica subjacente. Há uma premissa implícita de que o estado inicial seja de estabilidade e certeza ambiental relativa. $\mathrm{N}$ ão se trata de uma premissa "heróica". As relações transacionais em canal, independentemente das circunstâncias sob as quais se formem, são estruturadas sobre premissas explícitas e implícitas quanto ao ambiente. É no momento em que essas premissas não mais se sustentam, pois os ambientes mudam significativamente, que os membros do canal experimentam incerteza. Assim, é de se esperar 
que se instale uma dinâmica antes que seja atingido um novo estado de equilíbrio. As proposições a seguir voltam-se essencial mente para tal dinâmica.

Pelos motivos indicados no primeiro ponto acima, as proposições e a discussão das subseções seguintes servem apenas como aplicação ilustrativa e não exaustiva do arcabouço.

\section{Proposições ilustrativas: setores de insumos e de produção}

Sentimentos diádicos. Em canais de marketing, a incerteza que cerca a capacidade que uma díade tem de obter seus insumos e colocar seus produtos trará conseqüências profundas para os comportamentos e relacionamentos dos membros do canal. Um dos efeitos mais imediatos seria um aumento dos níveis de atrito e conflito percebido entre os membros da díade. Incertezas no setor de insumos, como falta ou variação na oferta de matériasprimas, produtos manufaturados ou peças, são freqüentemente atribuídas ao agente do canal que se encontra em primeiro lugar na cadeia de distribuição. Da mesma forma, incertezas no setor de produção, como flutuação da demanda ou queda das vendas, podem muitas vezes ser atribuídas à fraca capacidade de marketing dos agentes mais adiantados na cadeia. Como observou Assael (1969) em seu estudo dos canais automotivos:

Durante períodos de baixa demanda, os fabricantes costumam acusar as concessionárias de baixo desempenho e descumprimento de suas diretrizes quanto ao gerenciamento de varejo, promoção e políticas de preços; e as concessi onárias acusam os representantes das fabricantes de exercerem pressões injustificadas para forçar a conformidade, especialmente no que se refere à manutenção dos estoques. (ASSAEL, 1969, p. 573).

[...] políticas dos fabricantes aceitáveis durante períodos de prosperidade podem causar conflito quando as vendas caem. (ASSAEL, 1969, p. 576).

U ma proposição que ilustra o quanto a incerteza ambiental tende a influenciar o clima transacional ou os sentimentos em uma díade de marketing é a seguinte:

$P_{1}$ : Quanto maior a incerteza nos setores de insumos ou de produção do ambiente de tarefa das díades de canal de marketing, maior o nível de conflito interno da díade.

Coordenação. Se é nos sentimentos da díade que se manifestam os primeiros efeitos, o efeito seguinte mais provável seria uma alteração da maneira como se organizam as relações da díade. As díades de canal de marketing, como as organizações (confira Thompson, 1967), tendem a se proteger da incerteza externa. U ma maneira de lidar melhor com a incerteza externa é organizar-se melhor. A situação de el evada incerteza externa é enfrentada com um melhor planejamento, ações mais coordenadas e maior força competitiva. Em termos dinâmicos, seria de se prever que, com o aumento da incerteza, uma ou ambas as partes envidariam esforços para aumentar o nível de coordenação vertical. Tais esforços poderiam se refletir em termos da freqüência e intensidade de interação, e do grau de formalização/padronização de procedimentos diádicos.

$\mathrm{P}_{2}$ : Quanto maior a incerteza nos setores de insumos ou de produção do ambiente de tarefa das díades de canal de marketing, maiores os esforços para aumentar o nível de coordenação vertical da díade.

Equilíbrio de poder. A maior coordenação vertical é iniciada pelo agente do canal mais capacitado a lidar com a incerteza externa ou absorvê-la (Hickson et al., 1971). Assim, parece que mudanças no equilíbrio de poder (estrutura política) da díade mediam (e, portanto, devendo preceder) mudanças nos processos econômicos. A unidade que enfrentar um elevado grau de incerteza se tornará cada vez mais dependente da unidade que puder lidar da maneira mais eficaz com a incerteza externa em tela. Também, como observam Pfeffer e Salancik (1978), quando mais crítico for um recurso para o funcionamento eficaz do sistema como um todo e quanto mais incerta for a oferta desse recurso, mais provável será que haja esforços para controlar a disponibilidade do recurso. Quando é impossível obter controle direto do ambiente de insumos ou de produção, uma aproximação de controle pode ser obtida por meio do desenvolvimento de um elaborado sistema de informações para monitorar os setores rel evantes do ambiente de tarefa. 0 desenvolvimento bem-sucedido de tal sistema de informação para ambientes incertos de insumos ou de produção pode alterar o equilíbrio de poder das díades de canal em favor da parte encarregada da administração do sistema.

$P_{3}$ : Sob condições de incerteza ambiental, a direção da mudança do equilíbrio de poder nas díades de canal é determinada pelo membro capaz de lidar com as fontes 
de incerteza, absorvendo-as, em prol do outro. Além disso, a direção da mudança de poder também determina a direção da centralização dos processos de planejamento, coordenação e tomada de decisão ( processos econômicos).

Coordenação extradiádica. As proposições de $\mathrm{P}_{1}$ a $\mathrm{P}_{3}$ exploram os efeitos da incerteza nos setores de insumos e de produção sobre comportamentos intradiádicos. Ações coordenativas semelhantes podem ocorrer nos limites da díade de canal, ou seja, como coordenação vertical anterior ou posterior. Consideramos que a direção das ações de coordenação depende do setor onde surge a incerteza crítica.

$\mathrm{P}_{4}$ : Quanto maior a incerteza nos setores de insumos ou de produção do ambiente de tarefa das díades de canal de marketing, mais íntimos serão os el os verticais estabelecidos entre a díade e os outros agentes do canal. Se surge incerteza no setor de insumos, há tentativa de coordenação vertical posterior. Se ela surge no setor de produtos, a tentativa é de coordenação vertical anterior.

O fundamento lógico da proposição P4 é uma extensão dos argumentos de Thompson (1967) de que as organizações buscam poder sobre os el ementos de seus ambientes de tarefa dos quais mais dependem. A incerteza externa pode ser reduzida pelo uso de contratação, cooptação ou coalizão, que resultam em maior coordenação entre as organizações.

Descentralização vertical. Se o nível de conflito (ou de comportamento oportunista; veja Williamson, 1975) impedir a formação eficaz de mecanismos de coordenação intra- e extradiádicos e a incerteza perdurar, é provável que a díade se descentralize ou adote relacionamentos mais "frouxos". Isso normalmente significa que os distribuidores (atacadistas e varejistas) começarão a se ampliar e a se diferenciar por meio do acréscimo ou da eliminação de produtos, serviços e territórios geográficos. Assim reduz-se sua dependência com relação ao parceiro diádico original, e os produtores começam a empregar diversos canais, abrangendo uma variedade de distribuidores, de modo a reduzir, também, sua dependência.

$\mathrm{P}_{5}$ : Se a incerteza nos setores de insumos ou de produção do ambiente não puder ser absorvida pela integração/coordenação vertical ou por estratégias de "adaptação", o nível de conflito disfuncional irá aumentar, e é provável que a díade adote um relacionamento mais "frouxo".

\section{Proposições ilustrativas: setores competitivo e regulador}

As incertezas que emanam do setor competitivo e do regulador podem ser vistas como forças laterais que exercem impacto sobre a díade de canal. O nível de incerteza competitiva pode ser definido em termos de algumas das dimensões constantes da Figura 2. Por exemplo, quanto mais heterogêneos os competidores e quanto maior sua capacidade (porte e recursos) e mais intermediário seu nível de concentração competitiva (veja Pfeffer e Salanci, 1978, p. 124), maior a incerteza gerada pel o setor competitivo do ambiente de uma díade, permanecendo iguais as demais condições. A teoria relativa a essas dimensões permite um ajuste fino das proposições básicas que surgem da análise das incertezas de insumos-produção. Por exemplo, a proposição $P_{1}$ indica que as incertezas verticais aumentam os sentimentos de conflito nas díades de canal. Por outro lado, incertezas competitivas laterais podem levar a sentimentos menos conflituosos e mais cooperativos na díade de canal. Ameaças competitivas tendem a fazer com que a díade de canal se torne mais cooperativa porque são normalmente percebidas como movimentos de um inimigo comum. Uma conclusão notória da pesquisa em ciência comportamental é de que, quanto mais desgastante o conflito intergrupal, mais coesos e integrados se tornam os membros do grupo.

$P_{6}$ : Quanto maior a incerteza no setor competitivo do ambiente de tarefa das díades de canal de marketing, maior o nível de cooperação interna da díade.

A maior incerteza nos setores competitivos do ambiente de tarefa pode ser enfrentada por dois tipos de estratégias de canal, do ponto de vista das díades de canal. U ma delas é encarar os desafios competitivos com uma maior integração vertical ou, pelo menos, melhor coesão vertical. As atuais empresas de um setor podem diminuir substancialmente a incerteza competitiva seja (1) coordenando ou integrando de antemão para controlar fontes de matérias-primas, como minerais e petróleo; (2) coordenando ou integrando posteriormente para atrelar saídas para o varejo, como por meio da compra de postos de gasolina de excelente localização; e (3) ligando os clientes finais mais fortemente ao canal de marketing, como nos sistemas de distribuição de serviços de saúde (Aldrich, 1979; Scherer, 1980).

Outra estratégia disponível é formar arranjos cooperativos com os concorrentes. Mesmo que às vezes possam ser implementadas políticas públicas para res- 
tringir os esforços cooperativos entre os concorrentes, agentes inteligentes sempre encontrarão meios de superar parcialmente as restrições impostas. Essa estratégia, contudo, é considerada mais custosa, dado o impulso em direção à autonomia da díade e as normas e os regulamentos vigentes, pelo menos nos Estados Unidos, contra a limitação da competição.

$\mathrm{P}_{7}$ : Se a incerteza do setor competitivo do ambiente de tarefa das díades de canal de marketing não puder ser absorvida por coorden ação vertical, formam-se el os mais fortes com os competidores em cada nível do canal.

Incertezas quanto aos setores de insumos, de produção e competitivo podem levar um agente do canal a conceber estratégias para aumentar seu poder nas trocas diádicas. Mas o uso subseqüente desse poder e a subordinação diádica a ele são muitas vezes circunscritos pela regulamentação sob a forma de restrições legais específicas e/ou normativas. De modo geral, lidar com o setor regulador, adaptar-se à incerteza e trabalhar com as dependências externas tendem a ser, novamente, dimensões críticas enfrentadas pelas díades de canal. A incerteza que emana do setor regulador pode ser definida em termos de al gumas das variáveis constantes da Figura 2 . Assim, quanto mais variáveis, concentradas e heterogêneas forem as organizações reguladoras do ambiente de uma díade, mais incerto tenderá a ser 0 ambiente regulador.

Se a certeza-incerteza reguladora é definida em termos de certeza e clareza da capacidade do regulador para impor e fiscalizar a regulamentação, os efeitos da incerteza sobre o comportamento diádico tendem a ser diferentes dos propostos para os setores de insumos, de produção e competitivo. Isso porque a pressão ambiental em favor a uma resposta vertical mente coordenada e integrada à ameaça reguladora tende a ser função direta da certeza da descoberta e da sanção em caso de descumprimento. Se 0 ambiente regulador for incerto devido a reguladores heterogêneos e variáveis, os membros do canal terão melhores condições de correr o risco de descumprimento e dese defender por meio de trade-offs entre os diversos reguladores e suas exigências conflitantes.

$\mathrm{P}_{8}$ : Quanto maior a certeza do ambiente regulador, mais cooperativo, coordenado e integrado será o comportamento da díade em resposta às exigências regulamentares.

Contudo, as díades de canal de marketing não são receptoras passivas das forças do setor regulador de seus ambientes de tarefa. A pressão reguladora e as ações que restringem a atividade no canal (cf. Mitnick, 1980) normal mente são combatidas por meio de ações políticas e comportamento de coalizão por parte das díades de canal. Quanto mais incerto o ambiente regulador, maior a oportunidade de coordenação horizontal e ação política eficazes.

$P_{9}$ : Sob condições de incerteza reguladora, as díades de canal de marketing tendem a formar coalizões de interesses com agentes dos setores de insumos, de produção e competitivo de seu ambiente de tarefa para combater a incerteza do setor regulador.

A organização em um setor do ambiente de tarefa (como os atos no setor regulador) gera organização nos demais setores (como a formação de sindicatos patronais e grupos de pressão) para combater a incerteza externa enfrentada. 0 fenômeno pode ser interpretado em termos de contraposição de poder, mas também pode ser visto como um fenômeno normal numa sociedade pluralista, dotada de mercados de interesses sociais, políticos e econômicos correspondentes a um contexto estrutural poliárquico de controle social (Zald, 1978). Quando o contexto regulador é de natureza predominantemente poliárquica, decorre que os agentes afetados pela regulamentação também podem tentar influenciar diretamente os agentes reguladores, travando com eles relações de troca. Tais relações parecem ser cada vez mais comuns (veja Arndt, 1979) na maioria dos países.

$P_{10}$ : Se a incerteza no setor regulador do ambiente de tarefa das díades de canal de marketing não puder ser absorvida pelo comportamento de coalizão, essas díades tenderão a estabelecer elos mais íntimos com os agentes reguladores.

\section{CONCLUSÃO}

0 arcabouço de economia política para a anál ise comparada de canais de marketing proposto por Stern e Reve (1980) se concentrou nas interações internas às díades de canal. Neste artigo, o arcabouço original é ampliado para abranger o impacto de forças ambientais sobre a estrutura e os processos diádicos. A té hoje, este último tema tem sido ignorado, especialmente em estudos empíricos, devido às dificuldades conceituais e metodológicas a ele associadas. Esperamos que o arcabouço ora proposto torne o tema mais tratável. 
Consideramos aqui que o ambiente pode ser decomposto em seus ambientes primário, secundário e macro, e em seus setores de insumos, de produção, competitivo e regulador. 0 s agentes do ambiente primário são aqueles com que a díade mantém trocas diretas. 0 arcabouço de economia política de Stern-Reve (1980) é aplicável a essas interações. Mas exige-se um maior nível de dimensionamento e indução teórica para lidar com forças externas geradas por fatores extra-intercâmbio. Neste artigo, consideramos que a aplicação de construtos e teorias que representem os principais paradigmas do campo do comportamento macro de organizações tende a ser útil para o estudo dos efeitos dessas outras forças externas sobre o comportamento diádico. N esse contexto, o construto da incerteza foi empregado como exemplo, e foram fornecidas proposições ilustrativas.

Boa parte dos temas aqui abordados não é radicalmente nova. É de se esperar que o leitor familiarizado com a teoria das organizações também o esteja com muitos dos conceitos aqui levantados, e que algumas das proposições não pareçam controversas. 0 objetivo do arcabouço não é chocar, mas reunir explicações organizacionais relativamente desenvolvidas num todo mais coeso e compreensível nos contextos específicos dos canais de marketing. Assim sendo, sua principal contribuição deve estar em sua inter seção com o arcabouço de economia política interna. Como indicam as proposições ilustrativas, a atenção deve se debruçar sobre 0 efeito das forças ambientais na estrutura e nos processos das díades de canal porque, obviamente, a meta final de pesquisa nessa tradição deve ser a sugestão de uma maneira mais eficaz de administrar as relações nos canais de marketing. É com a administração dessas relações que se obterá melhor desempenho diádico. 0 abrangente arcabouço ora oferecido pela combinação daquele aqui proposto com 0 anterior (Stern e Reve, 1980) pode ser usado para levantar um sem-número de questões ainda não abordadas relacionadas ao desempenho dos canais. ${ }^{4}$ Por exemplo, se elevados níveis de incerteza ambiental acabam por levar a uma maior coordenação vertical, que forma essa coordenação deve assumir e como deve ser realizada para gerar um desempenho ótimo? Será melhor contar com transações de quase-mercado mediadas por negociação e barganha, onde o poder é freqüentemente desequilibrado e os processos de conflito são freqüentes, ou melhor lidar com transações hierárquicas em que o poder esteja total mente centralizado, mas os processos de conflito possam ser, de algum modo, amortecidos? (Veja em Thompson e Tuden, 1959; e Van de Ven e Ferry, 1980, p. 93, alguns esclarecimentos sobre a relação entre incerteza e consenso quanto a metas e estratégias de tomada de decisão). Da mesma forma, surgem perguntas importantes quanto à interação entre estados ambientais e os mecanismos administrativos (bases de poder, por exemplo) disponíveis para exercer controle ou gerenciar o conflito numa díade (Perrow, 1967, p. 200, por exemplo, explica que diferentes estratégias de influência podem ser mais eficazes sob diferentes estados ambientais).

Com efeito, um arcabouço abrangente, com todas as complexidades que traz em si, nada mais é, na verdade, do que um mapa de percurso. Limita-se a apontar a ampla gama de rotas que se pode seguir para atingir um determinado destino, mas não indica todos os obstáculos existentes no caminho ou a disponibilidade de determinados ben efícios que podem ser obtidos viajando-se por uma rota e não por outra. Esse é 0 papel do teste de teorias. Esperamos que o arcabouço atenda ao propósito de uma estrutura de referência e coordenação para se testarem teorias com eficiência. A contribuição dos arcabouços combinados deve ser vista, portanto, como um primeiro passo, pequeno mas necessário, à luz do esforço que resta fazer para aplicar os arcabouços à tarefa de ligar estrutura e processo ao desempenho. Este é certamente o maior desafio que o campo precisa abordar antes de avançar e aumentar sua relevância administrativa.

\section{NOTAS}

\begin{abstract}
${ }^{1}$ Para os ambientes secundário e macro, o esquema de classificação diverge da linguagem do arcabouço de economia política (estruturas e processos econômicos e políticos) porque acreditamos ser de menor utilidade segregar as forças econômicas e políticas ao caracterizar 0 ambiente externo. Ao lidar com o ambiente, a gestalt da economia política dentro da qual os membros do canal operam é, freqüentemente, mais importante para a compreensão das estruturas e processos que tipificam suas interações do que um entendimento dos componentes específicos de tal gestalt, classificados em torno de linhas políticas ou econômicas. Isso corresponde a uma abordagem de economia institucional em que as forças econômicas e políticas interagem ao moldarem o comportamento e os resultados coletivos.
\end{abstract}

\footnotetext{
2 Essa é basicamente a definição de Levine e W hite (1961, p. 588). Mas sua definição se concentrava na atividade voluntária. Acreditamos que nem todos os intercâmbios sejam necessariamente voluntários para ambos os lados. Por exemplo, os membros da díade podem ser forçados a participar de intercâmbios e relacionamentos com órgãos reguladores.
} 


\section{RAE CLÁSSICOS • O AMBIENTE DAS DÍADES DE CANAL DE MARKETING: UM ARCABOUÇO PARA ANÁLISES COMPARATIVAS}

${ }^{3} \mathrm{Em}$ termos dos efeitos dependentes e das estratégias organizacionais neles implícitas, o presente conjunto de possibilidades é abordado no excelente tratamento dado por Pfeffer e Salancik (1978) a fusões, diversificação, coordenação, cooperação, joint ventures, cooptação e associação, coalizão e formação de cartel.

${ }^{4} \mathrm{Q}$ uanto às diversas proposições que relacionam a economia política interna das díades ao desempenho, o leitor é encorajado a rever Stern e Reve (1980). Este artigo se concentrou na relação entre o ambiente e a estrutura e processos encontradiços nas díades de canal. Evitamos conscientemente repetir nossas posições sobre os elos entre estrutura, comportamento e desempenho, tratadas no artigo anterior.

Este artigo é de propriedade exclusiva da American Marketing Association, tanto quanto sua licença para uso, e é protegido pelo Copyright e pelas leis de propriedade intelectual. É um material destinado a uso pessoal e não comercial. Qualquer outro tipo de uso deste artigo é estritamente proibido. 0 usuário não poderá modificar, publicar, transmitir, participar na transferência ou na venda do material, reproduzir, criar trabal hos derivados (inclusive material didático) deste, distribuir, realizar apresentação ou fazer qualquer utilização do seu conteúdo, inteiro ou em partes. Este artigo foi traduzido objetivando expressamente esta publicação. A American M arketing Association não assumirá nenhuma responsabilidade por erros de interpretação causados pela tradução. 0 artigo "The environment of marketing channel dyads: a framework for comparative analysis", dos autores Ravi Singh Achrol, Torger Reve e Louis W. Stern, foi originalmente publicado no Journal of Marketing, volume 47 (Fall 1983), p. 55-67, e reproduzido com sua autorização.

\section{REFERÊNCIAS BIBLIOGRÁFICAS}

AIKEN, M.; ALFORD, R. Community structure and innovation: the case of public housing. TheAmerican Political Science Review, v. 64, n. 3, p. 843864, Sept. 1970.

ALDRICH, H. E. An Organization-environment perspective on cooperation and conflict between organizations in the manpower training system. In: NEGADHI, A. R. (Ed.). Interorganizational Theory. Kent, OH: Kent State University Press, 1975.

ALDRICH, H. E. Organizations and Environments. Englewood Cliffs, NJ: Prentice-Hall, 1979.

ALDRICH, H. E.; WHETTEN, D. Organization-sets, action-sets, and networks: making the most of simplicity. In: NYSTROM, P.; STARBUCK, W. (Eds.). Handbook of Organizational D esign. N ew York: Oxford University Press, 1981. p. 385-408.

ARNDT, J. Toward a concept of domesticated markets. Journal of Marketing, v. 43, n. 4, p. 69-75, 1979.

ASSAEL, H. Constructive role of interorganizational conflict. Administrative Science Quarterly, v. 14, n. 4, p. 573-582, 1969.

BAGOZZI, R. Marketing as exchange: a theory of transactions in the marketplace. American Behavioral Scientist, v. 21, n. 4, p. 353-556, 1978.
BLACK, B.; KASE, H. Interagency cooperation in rehabilitation and mental health. Social Service Review, v. 37, n. 1, p. 26-32, 1963.

BONOMA, T. V.; BAGOZZI, R. P.; ZALTMAN, G. The dyadic paradigm in marketing thought. In: BONOMA, T.; ZALTMAN, G. (Eds.). Organizational Buying Behavior. Chicago: American Marketing Association, 1978. p. 49-66.

BUCKLIN, L. P.; CARMAN, J. M. Vertical market structure theory and the health care delivery system. In: SHETH, N. J.; W RIGHT, P. L. (Eds.). Marketing Analysis for Societal Problems. Urbana, IL: University of Illinois, Bureau of Economic and Business Research, 1974. p. 7-39.

CARM AN, J. Paradigms for marketing theory. In: SHETH, J. (Ed.). Research in Marketing. Greenwich, CT: Jai Press, 1980. p. 1-36.

CHILD, J. Organizational structure, environment and performance: the role of strategic choice. Sociology, v. 6, n. 1, p. 2-22, 1972.

DILL, W. R. Environment as an influence on managerial autonomy. Administrative Science Quarterly, v. 2, n. 4, p. 407-443, 1958.

DUNCAN, R. B. Characteristics of organizational environments and perceived environmental uncertainty. Administrative Science Quarterly, v. 17, n. 3, p. 313-327, 1972.

EMERY, F. E.; TRIST, E. L. The causal texture of organizational environments. Human Relations, v. 18, n. 1, p. 21-32, 1965.

ETGAR, M. Channel environment and channel leadership. Journal of M arketing Research, v. 14, n. 1, p. 69-76, Feb. 1977.

EVANS, F. B. Selling as a dyadic relationship: a new approach. TheAmerican Behavioral Scientist, v. 6, n. 9, p. 76-79, 1963.

HICKSON, D. J.; LEE, C. A.; SCHNECK. R. E.; PEN NINGS, J. M. A strategic contingencies theory of intraorganizational power. Administrative Science Quarterly, v. 16, n. 2, p. 216-229, 1971.

JURKOVICH, R. A core typology of organizational environments. Administrative Science Quarterly, v. 19, n. 3, p. 380-294, 1974.

LAWRENCE, P.; LORSCH, J. Organization and Environment. Cambridge, MA: Harvard Business School, 1967.

LAWRENCE, R. P. The Harvard organization and environment research program. In: VAN DE VEN, A.; JOYCE, W. F. (Eds.). Perspectives on Organization Design and Behavior. New York: John Wiley, 1981. p. 311-337.

LEVINE, S.; WHITE, P. E. Exchange as a conceptual framework for the study of interorganizational relationships. Administrative Science Quarterly, v. 5, n. 4 , p. 583-601, 1961.

MITNICK, B. M. The Political Economy of Regulation: Creating, Designing, and Removing Regulatory Forms. New York: Columbia University Press, 1980. 


\section{RAVI SINGH ACHROL •TORGER REVE •LOUIS W. STERN}

PERROW, C. A framework for the comparative analysis of organizations. American Sociological Review, v. 32, n. 2, p. 194-208, 1967.

PFEFFER, J.; SALANCIK, G. R. The External Control of Organizations. N ew York: Harper \& Row, 1978.

REVE, T.; STERN , L. W. The relationship between interorganizational form, transactional climate, and economic performance in vertical interfirm dyads. Working paper. Northwestern University, 1982.

SCHERER, F. M. Industrial Market Structure and Economic Performance. Chicago: Rand McN ally, 1980

SHETH, J. N. Buyer-seller interaction: a conceptual framework. In: ANDERSON, B. B. (Ed.). Advances in Consumer Research. Ann Arbor, MI: Association for Consumer Research, 1976. p. 382-386.

STARBUCK, W. H. Organizations and their environments. In: DUNNETTE, M. D. (Ed.). Handbook of Industrial and Organizational Psychology. Chicago: Rand McNally, 1976. p. 1069-1123.

STERN, L. W.; REVE, T. Distribution channels as political economies: a framework for comparative analysis. Journal of Marketing, v. 44, n. 3, p. $52-64,1980$.

STURDIVANT, F. D. Determinants of vertical integration in channel systems. In: HAAS, R. M. (Ed.). Science, Technology and M arketing. Chicago: American Marketing Association, 1966. p. 472-479.

\section{Artigo convidado. Aprovado em 01.02.2006.}

\section{Ravi Singh Achrol}

Professor de Marketing da George Washington University. Interesses de pesquisa na área de Marketing.

E-mail: achrol@gwu.edu

Endereço: School of Business, George Washington University, 307, Funger Hall 2201, G Street, NW - Washington, DC, 20052, USA.

\section{Torger Reve}

Professor de Estratégia e Logística da BI Norwegian School of Management.

Interesses de pesquisa nas áreas de Marketing, Estratégia e Logística.

E-mail: torger.reve@bi.no

Endereço: BI Norwegian School of Management, NO-0442, Oslo, Norway.

\section{Louis W. Stern}

Professor emérito de Marketing da Kellogg School of Management - N orthwestern University. Interesses de pesquisa na área de Marketing.

Email: Iwstern@kellogg.northwestern.edu

Endereço: Northwestern University, Kellogg School of Management, 2001 N. Sheridan Rd., Evanston - Illinois, 60208-2001, USA.
TERREBERRY, S. The evolution of organizational environments. Administrative Science Quarterly, v. 12, n. 4, p. 591-613, 1968.

THOMPSON, J. D. Organizations in Action. N ew York: McGraw-Hill, 1967.

N D : TUDEN, A. Strategies, Structures, and Processes of Organizational Decision. In: THOMPSON, J. D. et al. (Eds.). Comparative Studies in Administration. Pittsburgh, PA: University of Pittsburgh Press, 1959.

VAN DE VEN, A.; FERRY, D. L. Measuring and Assessing Organizations. New York: John Wiley, 1980.

VAN DE VEN, A.; JOYCE, W. F. (Eds.). Perspectives on Organization D esign and Behavior. New York: John Wiley, 1981.

WEICK, K. E. The Social Psychology of Organizing. Reading, MA: AddisonWesley, 1969

WILLIAMSON, O. E. Markets and Hierarchies: Analysis and Antitrust Implications. New York: Free Press, 1975.

ZALD, M. N. On the social control of industries. Social Forces, v. 57, n. 1, p. $79-102,1978$

ZALTMAN, G.; LEMASTERS, K.; HEFFRING, M. Theory Construction in Marketing. N ew York: John Wiley, 1982. 